\title{
Weaving Things Together
}

B oundaries. We start early with really basic ones like "mine" and "yours," (or at least "mine" and "not mine"). Other boundary work is similarly foundational, helping us tell the difference between make-believe and reality, his and hers, public and private, and human and animal. Education provides us with many more compartmentalizations. We learn about the difference between literature and mathematics, biology and physics, psychology and sociology. In fact, the more education we pursue, the more boundaries we see set. We learn how every area of study is made up of many subspecialties, each with its own technologies and language.

Many people in the world don't sit comfortably within boundaries. Some people are inclined to work back and forth across carefully drawn and defended borders to engage sometimes far flung pieces of information in order to weave things together. I understand restoration ecologists to be members of this group. Some restorationists make connections, for example, between plants, microbes, soil type, and the behavior of hoofed animals. Others work to enlighten a park engineering project with information about how urban watershed hydrology, chemicals used in parking refinishing, and climate change all influence plant communities.

This is often knotty, complicated work. There are usually more factors than sit easily within conventional experimental design. This is also exciting work. Tremendous possibility lies outside of set boundaries, including the potential to solve problems that remain impervious to disciplinary efforts. This is my first issue as editor of Ecological Restoration and I am inspired and honored to be part of this challenging and exciting work.

In the last editorial for $E R$, William R. Jordan reminisced about this journal's first issue. Clearly, the appointment of a new editor is another sort of beginning, and the University of Wisconsin-Madison Arboretum staff has been very supportive of reflective, big-picture thinking. I look forward to conversations with many of you about new directions for the journal.

On a more immediate note, $E R$ received many manuscripts in the past year and I am happy to report that although the transition between editors put us behind, we are steadily working our way through submissions.

Ecological Restoration Vol. 25, No. 2, 2007

ISSN 1522-4740 E-ISSN 1543-4079

(O2007 by the Board of Regents of the University of Wisconsin System.
Also, to celebrate the strong visual element of restoration we are now including color photos on the back of the journal. Please include color photos with your article submissions!

The credit for editing the articles in this issue lies firmly with ER's science editor Joy Zedler, who shepherded manuscripts along during the gap between Dave Egan's departure and my arrival. The articles she helped produce relay the complexities of restoration and the work of stitching things together. Yongbo Liu and colleagues report on groundwater recharge in China, drawing connections between farmers, climate change and water management policy. Shannon Galbraith-Kent and others describe the challenges faced in restoring park land in New York City. UW Arboretum staff member Steve Glass shares what he learned about Australian rainforest restoration, including the power of volunteers and how theory drives specific planting regimes. Jon Piper reports on experiments with seed mixes from a variety of plants in a Kansas prairie, and Stephen Murphy and colleagues take on the often real-world situation of under-funded restoration efforts in their work assessing different approaches to invasive species management (it turns out sometimes doing a little is worse than doing nothing). Roger Anderson and his undergraduate students share results from an assessment of prairie restoration in Illinois and Roger Latham and his colleagues discuss some surprising inter-species interactions in endangered fritillary butterfly habitat management (it turns out military training activity plays an key positive role).

I hope to meet many of you-perhaps at the ESA/SER conference? I look forward to good conversations about the multi-faceted, exciting business of weaving things together.

Finally, I'd like to pay tribute to Ken Sullivan, who helped market Ecological Restoration through the University of Wisconsin Press and who passed away unexpectedly in late April. Ken helped us find new audiences for the journal as the field has expanded. He was also a talented graphics artist and leant his hand when we needed assistance (for example, he compiled the map on page 95). We will miss his easy-going style, creativity, enthusiasm, and professional approach.

\section{Mrill Ingram}

